\title{
Xác định đồng thời Nisin A và Nisin Z trong sản phẩm dinh dưỡng bằng sắc ký lỏng khối phổ hai lần (LC-MS/MS)
}

Trần Thị Hường ${ }^{1,2^{*}}$, Lê Thị Thúy $y^{3}$ Vũ Thị Trang ${ }^{3}$

Nguyễn Thị Ánh Hường ${ }^{1}$ Lê Thị Hồng Hảo ${ }^{1,3^{*}}$

${ }^{1}$ Truiơng Đại học Khoa học Tự nhiên, Đại học Quốc gia Hà Nội, Việt Nam

${ }^{2}$ Trung tâm Kiêm soát bệnh tật tỉnh Nam Định, Nam Định, Việt Nam

${ }^{3}$ Viện Kiểm nghiệm an toàn vệ sinh thực phâm quốc gia, Hà Nội, Việt Nam

(Ngày đến tòa soạn: 16/11/2020; Ngày chấp nhận đăng: 05/02/2021)

\section{Tóm tắt}

Nghiên cứu này phát triển phương pháp xác định đồng thời Nisin $\mathrm{A}$ và Nisin $\mathrm{Z}$ trong các sản phẩm dinh dưỡng bằng LC-MS/MS. Các chất phân tích được chiết siêu âm ra khỏi nền mẫu bằng hỗn hợp dung dịch đệm $\mathrm{CH}_{3} \mathrm{COONH}_{4} 0,1 \mathrm{M}-\mathrm{NaCl} 1 \mathrm{M}(\mathrm{pH}=2) / \mathrm{MeOH}(1 / 1, \mathrm{v} / \mathrm{v})$

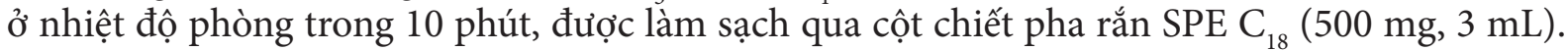
Dịch chiết sau khi làm sạch được tách bằng sắc ký lỏng sử dụng cột $\mathrm{C}_{18}(100 \mathrm{~mm} \times 2 \mathrm{~mm} \times 1,7$ $\mu \mathrm{m})$, định lượng bằng detector khối phổ với chế độ ESI $(+)$. Thẩm định phương pháp cho kết quả đường chuẩn tuyến tính trong khoảng 5,00 - $1.000 \mu \mathrm{g} / \mathrm{L}$; RSD 2,12 - 5,77\%; độ thu hồi 80,1 - 105\% phương pháp đạt yêu câuu AOAC. Phương pháp đã được áp dụng để phân tích 25 mẫu thực phẩm dinh dưỡng thu thập trên thị trường (bao gồm: sữa lỏng, sữa bột, bơ, phomat, bột dinh dưỡng) cho kết quả 02 mẫu phát hiện đông thời Nisin $\mathrm{A}$ và Nisin $\mathrm{Z}$.

Từ khóa: LC-MS/MS, Nisin A, Nisin Z, thực phâm, sản phẩm dinh dương.

\section{1. ĐẠT VẤN ĐỀ}

Cùng với sự phát triển của công nghiệp thực phẩm, để tạo ra nhiều sản phẩm phù hợp với sở thích và khẩu vị của người tiêu dùng mà vẫn giữ được chất lượng toàn vẹn của thực phẩm cho đến khi sử dụng, trong quá trình chế biến, nhà sản xuất đã sử dụng các nhóm chất bảo quản để tăng giá trị thương phẩm và kéo dài thời gian sử dụng của thực phẩm. Đa số các chất bảo quản hiện nay được tổng hợp nhân tạo đã gây ra nhiều tác dụng phụ không mong muốn do khó bị phân huỷ và để lại dư lượng trong thực phẩm. Các nhà nghiên cứu cũng như các nhà sản xuất ngày càng có xu hướng sử dụng các chất bảo quản có nguồn gốc sinh học, tự nhiên để dân thay thế chất bảo quản có nguồn gốc hóa học, mà vẫn đáp ứng được nhu câu tiêu dùng các loại thực phẩm an toàn, đảm bảo chất lượng, kéo dài được thời gian sử dụng. Việc sử dụng các chất kháng khuẩn có nguôn gốc sinh học như bacteriocin, đặc biệt là Nisin $\mathrm{A}$ và Nisin $\mathrm{Z}$ trong bảo quản, chế biến thực phẩm đang được quan tâm nhiều. Ngoài khắc phục được những nhược điểm của phương pháp sử dụng hoá chất, nhiệt độ, chiếu xạ,... Nisin còn có nhiều ưu điểm khác như phạm vi ứng dụng rộng, giảm thời gian và nhiệt độ thanh trùng của sản phẩm, đảm bảo chất lượng, giá trị dinh dưỡng, cảm quan vị sản phẩm. Ủy ban chuyên gia quốc tế về phụ gia thực phẩm (JECFA) đưa ra mức tiêu thụ tối đa chấp nhận hàng ngày (ADI) của các hợp chất này là $0,13 \mathrm{mg} / \mathrm{kg}$ thể trọng/ngày. Tại Việt Nam, theo quy định tại thông tư 24/2019/TT-BYT của Bộ Y tế [1], giới hạn tối đa của Nisin trong phomat, đồ uống và đồ tráng miệng từ sữa là $12,5 \mathrm{mg} / \mathrm{kg}$.

\begin{tabular}{ll}
\hline Điện thoại: 0942498837 & Email: minhanhytdpnd@gmail.com \\
Điện thoại: 0904248167 & Email: lethihonghao@yahoo.com
\end{tabular}


Trên thế giới đã có một số nghiên cứu được công bố vể phương pháp xác định riêng rẽ hoặc đồng thời Nisin $\mathrm{A}$ và Nisin $\mathrm{Z}$ bao gồm: phương pháp sinh học, sắc ký lỏng hiệu năng cao (HPLC) với detector UV-Vis [2]; điện di mao quản (CE) [3-4], sắc ký lỏng khối phổ (LC-MS/ MS) [5-8]. Phương pháp HPLC, CE hay sinh học thường khá phức tạp và kém chính xác do ảnh hưởng của nền mẫu cũng như kích thước lớn của phân tử Nisin. Ở Việt Nam, tiêu chuẩn TCVN 10137: 2013 (ISO/TS 27106:2009) được sử dụng để xác định Nisin A [5], nhưng chưa đề cập đến việc xác định đồng thời Nisin Z. Ngoài ra, quy trình xử lý mẫu theo TCVN 10137: 2013 phức tạp và tốn nhiêu thời gian phân tích. Trong khi đó, do Nisin $Z$ hòa tan tốt hơn so với Nisin $\mathrm{A}$ nên các nhà sản xuất đã sử dụng kết hợp Nisin $\mathrm{A}$ và Nisin $\mathrm{Z}$ hoặc riêng lẻ từng chất để bảo quản thực phẩm. Vì vậy, cần có một quy trình tối ưu có thể xác định được đông thời Nisin $A$ và Nisin $Z$ trong thực phẩm nói chung và các sản phẩm dinh dưỡng nói riêng. Phương pháp LC-MS/MS có ưu điểm như: phân tích nhanh, tiết kiệm thời gian và dung môi, độ nhạy cao và nhận diện được đông thời các hợp chất có tính chất và cấu trúc tương đông nhau nên đã được lựa chọn để xác định đồng thời Nisin $\mathrm{A}$ và Nisin $\mathrm{Z}$ trong nghiên cứu này.

\section{VẠT LIỆU VÀ PHƯƠNG PHÁP NGHIÊN CƯU}

\subsection{Nguyên vật liệu}

Các hóa chất sử dụng trong nghiên cứu đêu thuộc loại tinh khiết phân tích dùng cho sắc ký lỏng khối phổ hai lần.

Các chất chuẩn gồm có: Nisin A từ Sigma Aldrich (St. Louis, $\mathrm{MO}$ ), Nisin Z tù̀ Zhejiang Silver-Elephant Bio-Engineering Co. Ltd. (Tian Tai, Zhejiang), các hoá chất: acetonitril, methanol, amoni acetate, isopropanol (IPA), acid trifluoroacetic (TFA) từ Merck.

Mẫu nghiên cứu: 25 mẫu sản phẩm dinh dưỡng gồm sữa lỏng, sũa bột, bơ, phomai, bột dinh dưỡng được lấy ngẫu nhiên trên địa bàn thành phố Hà Nội.

\subsection{Thiết bị}

Hệ thống sắc ký lỏng khối phổ (LC-MS/MS) Waters Xevo TQ-XS; cột sắc ký Waters Acquity $\mathrm{BEH} \mathrm{C}_{18}(100 \times 2,1 \mathrm{~mm} ; 1,7 \mu \mathrm{m})$ và các thiết bị phụ trợ khác của phòng thí nghiệm.

\subsection{Phương pháp nghiên cứu}

\subsubsection{Phương pháp xủ̉ lý mẫu}

Cân chính xác khoảng $5 \mathrm{~g}$ mẫu đã đồng nhất vào ống falcon $50 \mathrm{~mL}$, thêm $30 \mathrm{~mL}$ dung dịch chiết: $\mathrm{CH}_{3} \mathrm{COONH}_{4} 0,1 \mathrm{M}-\mathrm{NaCl} 1 \mathrm{M}(\mathrm{pH}=2,0) / \mathrm{MeOH}(1 / 1, \mathrm{v} / \mathrm{v})$, lắc xoáy trong 1 phút. Lắc 10 phút trên máy lắc ngang, sau đó rung siêu âm trong vòng 10 phút. Ly tâm lạnh ở $4^{\circ} \mathrm{C}$ với tốc độ 6.000 vòng/phút trong 10 phút. Gạn dịch trong vào bình định mức $50 \mathrm{~mL}$, phân cặn được chiết lặp thêm 2 lần, mỗi lần với $10 \mathrm{~mL}$ dung dịch đệm chiết. Gộp dịch chiết vào vào bình định mức $50 \mathrm{~mL}$ và định mức đến vạch. Dịch chiết được lọc qua giấy lọc và làm sạch sử dụng cột chiết pha rắn $\mathrm{SPE}_{18}$, rửa giải bằng $6 \mathrm{~mL}$ hỗn hợp IPA/TFA $0,1 \%(70 / 30, \mathrm{v} / \mathrm{v})$, lọc qua màng lọc $0,22 \mu \mathrm{m}$ và phân tích trên hệ thống LC-MS/MS.

\subsection{2. Điều kiện phân tích LC-MS/MS}

Điều kiện khối phổ: Chế độ quan sát: MRM, kỹ thuật ion hóa: ESI (+), nhiệt độ buông ion hóa: $300^{\circ} \mathrm{C}$, tốc độ dòng khí $\mathrm{N}_{2}: 10 \mathrm{~L} /$ phút, điện áp mao quản: $2.000 \mathrm{~V}$ (Negative), Nebulizer: 40 psi, khoảng phổ khối scan: 2 - $2048 \mathrm{~m} / \mathrm{z}$, thời gian SCAN: $500 \mathrm{~ms}$. 
Điều kiện sắc ký lỏng: Pha động: kênh $\mathrm{A}$ : acid formic - nước $0,1 \%$ và kênh $\mathrm{B}$ : acetonitril với chế độ gradient: ổn định ở $90 \% \mathrm{~A}$ trong 1 phút, giảm xuống $50 \% \mathrm{~A}$ và giữ ổn định trong 2 phút, giảm xuống 20\% A và giữ ổn định trong 3 phút, tăng đến $90 \%$ A và giữ ổn định trong 2 phút. Tổng thời gian phân tích là 8 phút. Tốc độ dòng $0,15 \mathrm{~mL} /$ phút.

\section{KẾT QUẢ VÀ THẢO LUÂN}

\subsection{Lựa chọn điều kiện khối phổ}

Các thông số về điều kiện khối phổ nhằm phân tích đồng thời Nisin $\mathrm{A}$ và Nisin $\mathrm{Z}$ được tối ưu hóa tự động sử dụng phân mềm của thiết bị LC-MS/MS, kết quả được trình bày trong Bảng 1 .

Bảng 1. Các thông số khối phổ phân tích đồng thời Nisin A và Nisin Z

\begin{tabular}{|c|c|c|c|c|c|c|}
\hline $\begin{array}{l}\text { Chất phân } \\
\text { tích }\end{array}$ & $\begin{array}{c}\text { Khối lượng } \\
\text { phân tû̉ }\end{array}$ & $\begin{array}{l}\text { Thời gian } \\
\text { lưu (phút) }\end{array}$ & $\begin{array}{c}\text { Ion me } \\
(m / z)\end{array}$ & $\begin{array}{c}\text { Ion con } \\
(m / z)\end{array}$ & $\begin{array}{l}\text { Thế ion } \\
\text { hóa }(V)\end{array}$ & $\begin{array}{c}\text { Năng lượng va } \\
\text { chạm }(e V)\end{array}$ \\
\hline \multirow{2}{*}{ Nisin A } & \multirow{2}{*}{3358,53} & \multirow{2}{*}{4,09} & \multirow{2}{*}{671,6} & 788,9 & 46 & 14 \\
\hline & & & & $809,7^{\star}$ & 46 & 14 \\
\hline \multirow{2}{*}{ Nisin Z } & \multirow{2}{*}{3335,91} & \multirow{2}{*}{4,10} & \multirow{2}{*}{667,0} & 738,9 & 40 & 14 \\
\hline & & & & $805,3^{*}$ & 40 & 16 \\
\hline
\end{tabular}

Ghi chú: mảnh (*) là mảnh định lượng

Với chế độ ion hóa phun điện tử ESI (+), hợp chất Nisin A và Nisin $\mathrm{Z}$ được ion hóa theo cơ chế $[\mathrm{M}+5 \mathrm{H}]^{5+}$. Trong quá trình tách sắc ký, hai hợp chất Nisin $\mathrm{A}$ và Nisin $\mathrm{Z}$ không hoàn toàn tách biệt được khỏi nhau, tuy nhiên chúng có mảnh phổ khối khác nhau nên vẫn nhận diện và định lượng được chính xác bằng khối phổ.

\subsection{Tối ưu hóa điều kiện phân tích sắc ký lỏng}

\subsubsection{Khảo sát nông độ acid formic trong pha động}

Dựa vào cơ chế phân mảnh ion và qua tham khảo tài liệu [7-8] cho thấy, tín hiệu của Nisin $A$ và Nisin $\mathrm{Z}$ bị ảnh hưởng bởi nồng độ acid formic trong pha động. Tiến hành khảo sát thành phần pha động bằng việc thay đổi nồng độ acid formic với các giá trị: 0,$0 ; 0,05 ; 0,1 ; 0,2 ; 0,3 \%$ để tăng nông độ $\mathrm{H}^{+}$trong môi trường. Kết quả khảo sát nông độ acid formic được thể hiện ở Hình 1.

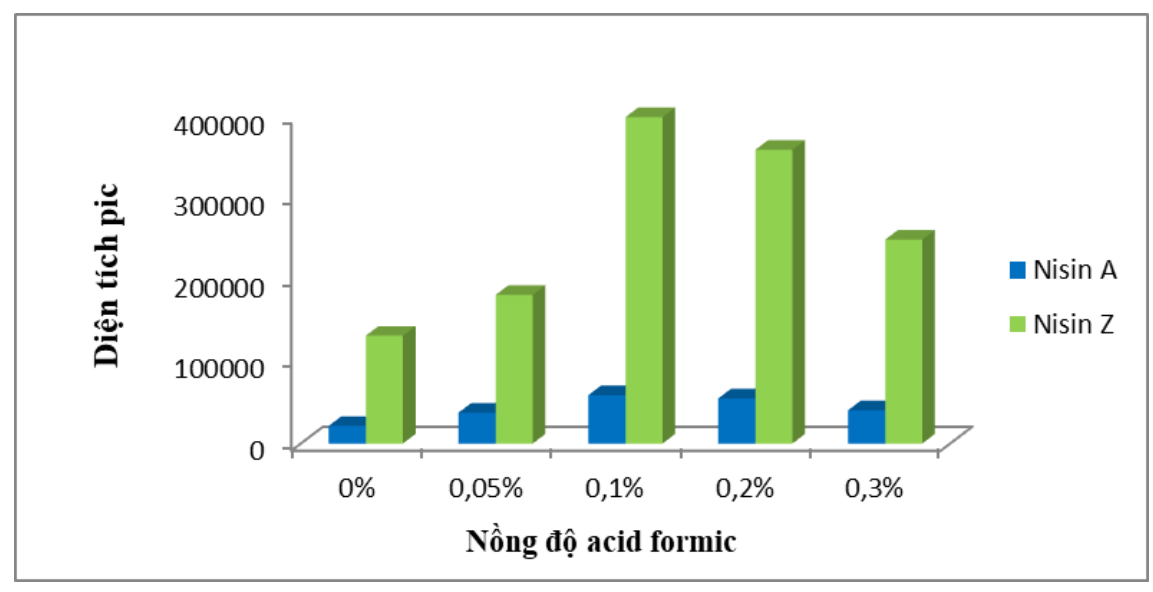

Hình 1. Anh huởng của nồng độ acid formic 
Từ kết quả khảo sát ở Hình 1 cho thấy, tín hiệu các chất phân tích bị ảnh hưởng khá nhiều bởi nồng độ acid formic trong pha động. Khi nồng độ acid formic thấp thì tín hiệu các chất phân tích thấp và ngược lại khi nồng độ acid formic tăng thì tín hiệu chất phân tích tăng, tuy nhiên khi nồng độ acid formic tăng quá cao dẫn đến hiện tượng cạnh tranh ion làm tín hiệu chất phân tích giảm. Tín hiệu đạt giá trị cao nhất khi nông độ acid formic là $0,1 \%$. Do đó, nông độ acid formic $0,1 \%$ được lựa chọn cho các khảo sát tiếp theo.

\subsubsection{Khảo sát chương trình rủa giải gradient}

Nisin $A$ và Nisin $Z$ có cấu trúc tương tự nhau, trong khi đó, nền mẫu thực phẩm dinh dưỡng phức tạp và có nhiều yếu tố gây ảnh hưởng. Do đó, để giảm thiểu ảnh hưởng của nền mẫu, đảm bảo độ nhạy của các chất phân tích, việc sử dụng chế độ rửa giải đẳng dòng (isocractic) là không phù hợp. Qua tham khảo tài liệu [5-8], để có thể vừa tách được các chất, vừa tiết kiệm thời gian phân tích và dung môi, chương trình rửa giải gradient được khảo sát như trong Bảng 2.

Bảng 2. Khảo sát chương trình rủa giải gradient

\begin{tabular}{|c|c|c|c|c|}
\hline $\begin{array}{l}\text { Chuoongtrinh } \\
\text { gradient }\end{array}$ & Thời gian (phút) & Tốc độ dòng (mL/phút) & $\begin{array}{c}\text { Kênh } A: \\
\text { acid formic } 0,1 \%\end{array}$ & Kênh B: ACN \\
\hline \multirow{4}{*}{ Gradient 1} & $0-1$ & 0,15 & 100 & 0 \\
\hline & $1,01-5$ & 0,15 & 30 & 70 \\
\hline & $5,01-8$ & 0,15 & 80 & 20 \\
\hline & $8,01-10$ & 0,15 & 100 & 0 \\
\hline \multirow{3}{*}{ Gradient 2} & $0-2$ & 0,15 & 90 & 10 \\
\hline & $2,01-6$ & 0,15 & 30 & 70 \\
\hline & $6,01-10$ & 0,15 & 90 & 10 \\
\hline \multirow{4}{*}{ Gradient 3} & 0 - 1 & 0,15 & 90 & 10 \\
\hline & $1,01-3$ & 0,15 & 50 & 50 \\
\hline & $3,01-6$ & 0,15 & 20 & 80 \\
\hline & $6,01-8$ & 0,15 & 90 & 10 \\
\hline
\end{tabular}

Kết quả ở Bảng 2 cho thấy, trong ba chế độ rửa giải gradient được khảo sát thì chế độ rửa giải 3 cho tín hiệu pic đẹp nhất, pic thu được không bị tù, không kéo đuôi và tín hiệu pic cũng cao nhất (Hình 2). Do đó, chương trình rửa giải gradient 3 được lựa chọn cho các nghiên cứu tiếp theo.
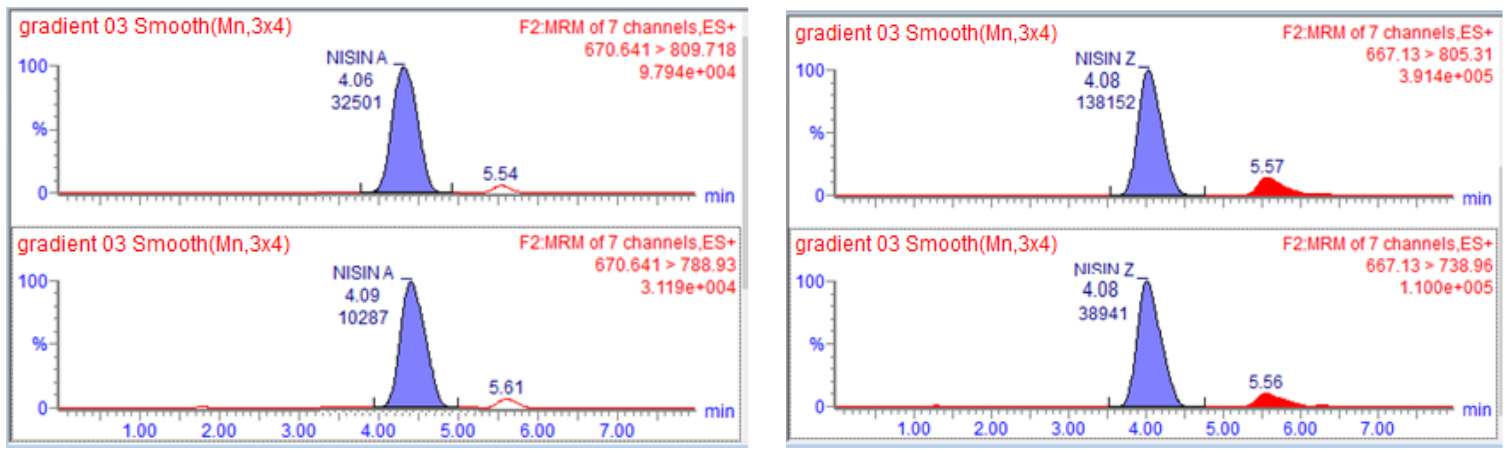

Hinh 2. Kết quả sắc đồ khi sủ̉ dụng chương trình rủa giải gradient 3 


\subsection{Tối ưu hóa điều kiện xử lý mẫu}

\subsubsection{Khảo sát nông dộ dung dịch đệm chiết}

Nồng độ dung dịch đệm chiết $\mathrm{CH}_{3} \mathrm{COONH}_{4}-\mathrm{NaCl}$ được khảo sát với các giá trị trong các khoảng $0,05-0,5 \mathrm{M}, 0,1-1,0 \mathrm{M}, 0,2-2,0 \mathrm{M}$ và $0,4-4,0 \mathrm{M}$. Kết quả thu được trong Hình 3 .

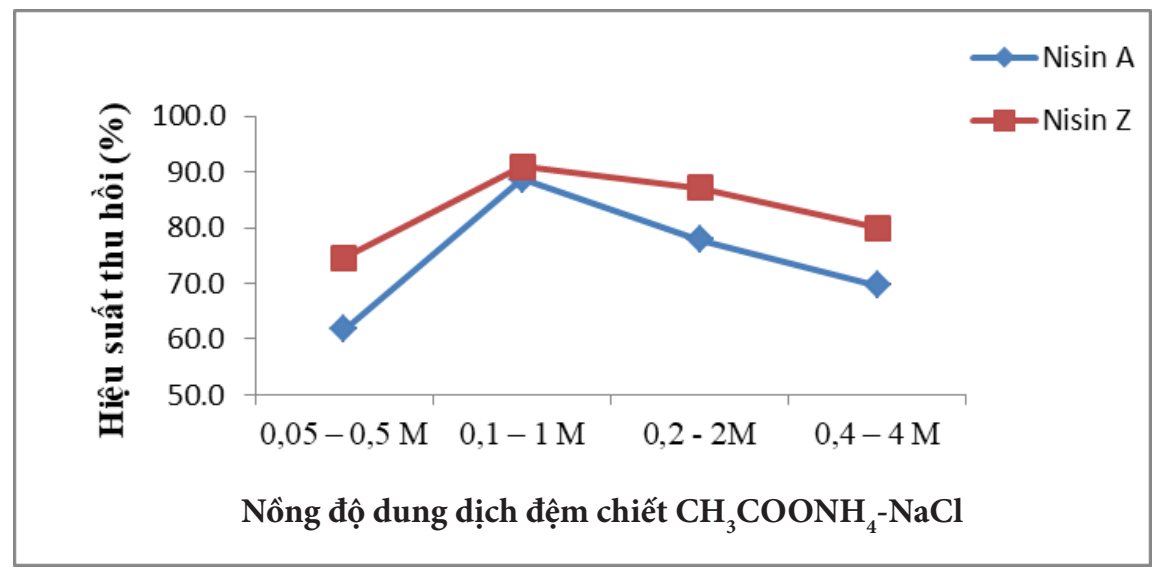

Hinh 3. Đồ thị ảnh hưởng của nông độ dung dịch đệm chiết mẫu

Kết quả cho thấy, khi thay đổi các khoảng nông độ từ $0,05-0,5 \mathrm{M}$ đến $0,4-4,0 \mathrm{M}$, hiệu suất thu hồi của các chất phân tích tăng dân và cao nhất tại nông độ dung dịch chiết $0,1 \mathrm{M}-1,0 \mathrm{M}$. Tuy nhiên, khi nồng độ tăng quá cao, hiệu suất thu hồi các chất giảm xuống do nông độ các ion trong mẫu cao dẫn đến sự cạnh tranh của các ion khi đi vào buông ion hóa, làm giảm tín hiệu của chất phân tích và có thể gây nhiễm bẩn buông ion hóa, ảnh hưởng đến hệ thống UPL, giảm tuổi thọ của cột phân tích. Do đó trong nghiên cứu này, hệ đệm $\mathrm{CH}_{3} \mathrm{COONH}_{4}-\mathrm{NaCl}$ nông độ $0,1-1,0 \mathrm{M}$ đã được lựa chọn để chiết chất phân tích từ nền mẫu.

\subsubsection{Khảo sát pH của dung môi chiết}

Ở môi trường $\mathrm{pH}$ khác nhau, trạng thái tôn tại của các Nisin là khác nhau, do đó sẽ ảnh hưởng đến việc hòa tan các chất phân tích trong mẫu. Dựa vào tính chất của Nisin và tham khảo tài liệu [7-9] cho thấy, khi $\mathrm{pH}$ của mẫu ở môi trường acid mạnh thì sự hòa tan của Nisin $\mathrm{A}$ và Nisin $\mathrm{Z}$ là tốt nhất. Do đó, sáu giá trị pH trong khoảng từ 2,0 - 6,6 đã được lựa chọn khảo sát, kết quả thể hiện trong Hình 4.

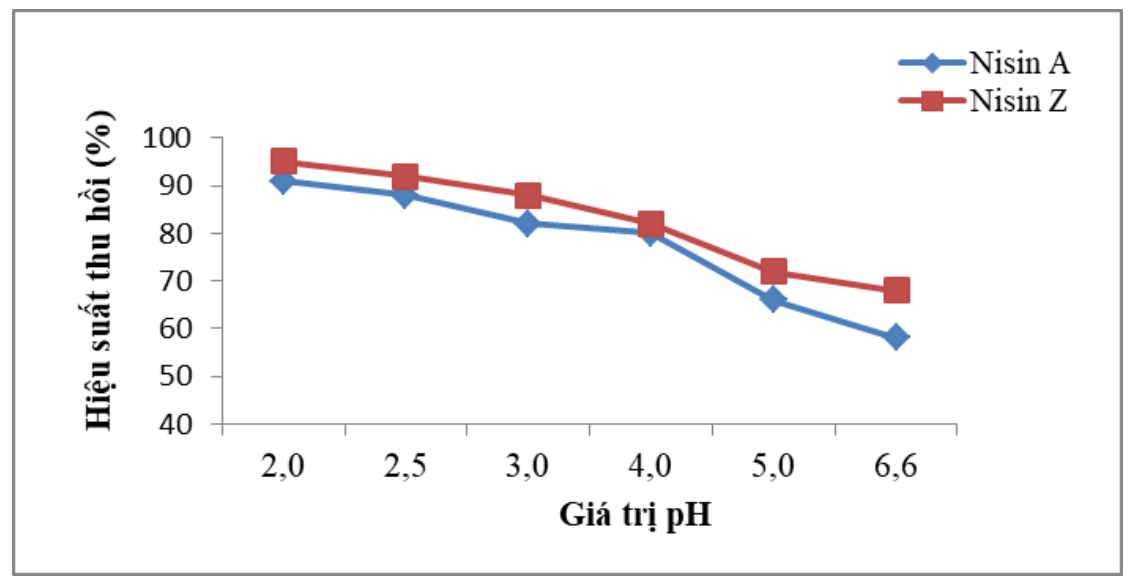

Hình 4. Đồ thị khảo sát ảnh hưởng của pH dung dịch đệm 
Kết quả khảo sát ở Hình 4 cho thấy, khi pH càng tăng thì hiệu suất thu hồi các chất phân tích càng giảm. Ở giá trị $\mathrm{pH}=2,0$ cho kết quả hiệu suất thu hồi của hai chất phân tích đạt cao nhất, phù hợp với tính chất hòa tan tốt và ổn định nhất trong môi trường acid này. Do đó, giá trị $\mathrm{pH}=2,0$ được lựa chọn cho các khảo sát tiếp theo.

\subsubsection{Khảo sát tỷ lẹ dung dịch chiết}

Thành phân dung dịch chiết $\mathrm{CH}_{3} \mathrm{COONH}_{4} 0,1 \mathrm{M}-\mathrm{NaCl} 1 \mathrm{M}(\mathrm{pH}=2) / \mathrm{MeOH}$ cũng được khảo sát với ba tỷ lệ là: $2 / 1,1 / 2,1 / 1$ nhằm thu được hiệu suất tốt nhất. Kết quả khảo sát được thể hiện trong Hình 5.

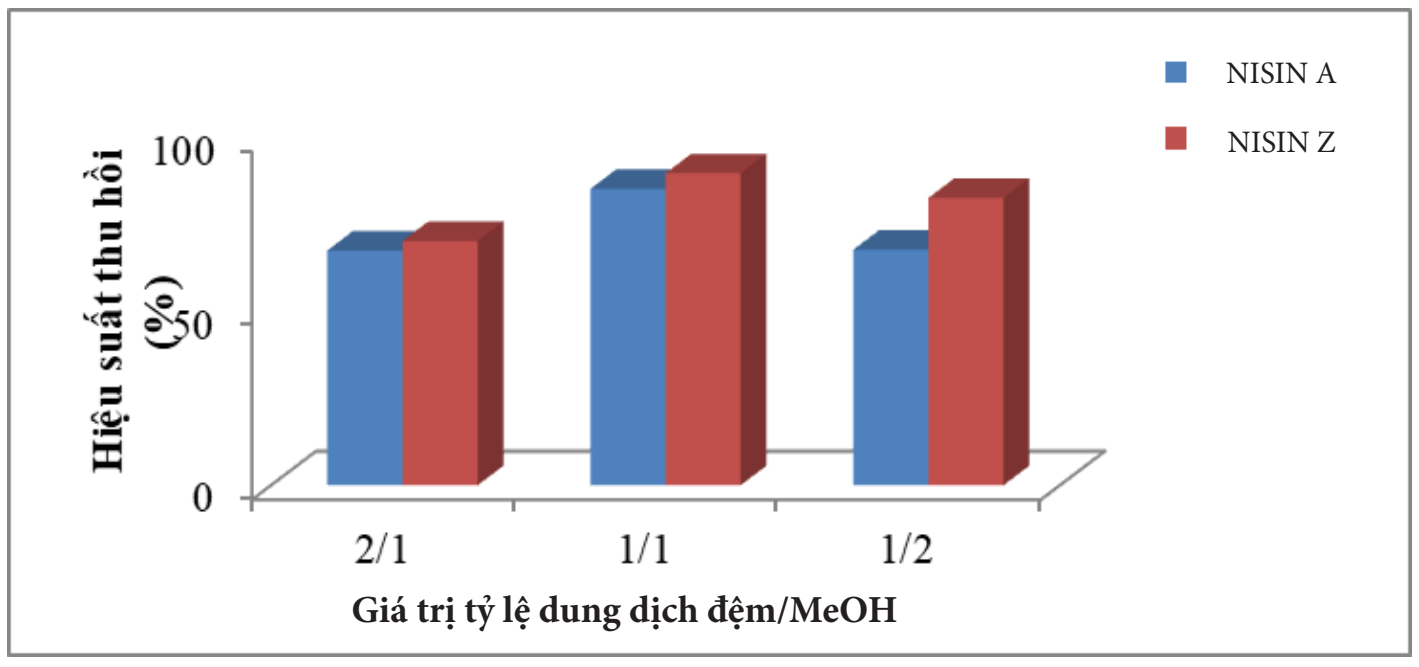

Hình 5. Kết quả khảo sát ảnh hưởng của tỷ lệ dung dịch đệm và $\mathrm{MeOH}$

Kết quả cho thấy, khi tăng thể tích $\mathrm{MeOH}$ trong hệ đệm chiết, hiệu suất thu hôi của Nisin $Z$ giảm đáng kể. Trong khi đó, khi tăng thể tích của dung dịch đệm thì hiệu suất thu hồi của cả Nisin $\mathrm{A}$ và $\mathrm{Z}$ đều giảm mạnh. Hiệu suất thu hồi của hai chất đạt cao nhất tại tỷ lệ dung dịch chiết $\mathrm{CH}_{3} \mathrm{COONH}_{4} 0,1 \mathrm{M}-\mathrm{NaCl} 1 \mathrm{M}(\mathrm{pH}=2) / \mathrm{MeOH}$ là $1 / 1$. Do đó, tỉ lệ giữa dung dịch đệm và $\mathrm{MeOH}(1 / 1, v / v)$ được lựa chọn cho các nghiên cứu tiếp theo.

\subsubsection{Khảo sát quá trình làm sạch mẫu}

Qua tham khảo tài liệu $[5-8,10]$, kỹ thuật chiết pha rắn $(\mathrm{SPE})$ với cột $\mathrm{C}_{18}$ - (Sulpeco, 500 $\mathrm{mg}, 3 \mathrm{~mL}$ ) được lựa chọn cho bước làm sạch mẫu. Kết quả khảo sát cho thấy, khi sử dụng cột $\mathrm{SPE}_{18}$ cho hiệu suất thu hồi cao hơn rất nhiều so với khi không sử dụng cột, đạt 92,6 - 100,0\%. Do đó, cột $\mathrm{SPE} \mathrm{C}_{18}$ được lựa chọn cho bước làm sạch mẫu trong nghiên cứu này.

\subsection{Thẩm định phương pháp}

Độ đặc hiệu của phương pháp được đánh giá thông qua việc phân tích mẫu trắng, mẫu chuẩn và mẫu thêm chuẩn. Kết quả chỉ ra mẫu trắng không cho tín hiệu chất phân tích, mẫu chuẩn và mẫu thêm chuẩn cho tín hiệu chất phân tích tại cùng thời gian lưu. Do đó, phương pháp có độ đặc hiệu tốt.

Trên cơ sở điều kiện phân tích tối ưu thu được, đường chuẩn phân tích Nisin $\mathrm{A}$ và Nisin $\mathrm{Z}$ đã được thiết lập trong khoảng nồng độ 5,00 - $1.000 \mu \mathrm{g} / \mathrm{L}$. Kết quả phương trình đường chuẩn, hệ số tương quan $\left(\mathrm{R}^{2}\right)$, giới hạn phát hiện $(\mathrm{MDL})$ và giới hạn định lượng $(\mathrm{MQL})$ của phương pháp, độ lặp lại (RSD) và độ thu hồi $(\mathrm{H})$ của các chất phân tích được trình bày trong Bảng 3 . 
Bảng 3. Kết quả đánh giá phương pháp phân tích

\begin{tabular}{|c|c|c|c|c|c|c|}
\hline $\begin{array}{l}\text { Tên chất } \\
\text { Phân tích }\end{array}$ & $\begin{array}{l}\text { Phương trình } \\
\text { đường chuẩn }\end{array}$ & $\begin{array}{c}\text { Hệ số tuiơng } \\
\text { quan } R^{2}\end{array}$ & $\begin{array}{c}M D L \\
(\mu g / k g / L)\end{array}$ & $\begin{array}{c}M Q L \\
(\mu g / k g / L)\end{array}$ & $\begin{array}{r}R S D \\
(\%)\end{array}$ & $\begin{array}{c}H \\
(\%)\end{array}$ \\
\hline Nisin $A$ & $\begin{array}{c}\mathrm{y}=(-14831 \pm 13521)+ \\
(3251 \pm 31) x\end{array}$ & 0,9996 & 5,5 & 18,2 & $\begin{array}{l}2,12- \\
3,52\end{array}$ & $80,1-105$ \\
\hline$N i \sin Z$ & $\begin{aligned} y= & (-156558 \pm 117317) \\
& +(27920 \pm 270) x\end{aligned}$ & 0,9997 & 4,9 & 16,4 & $\begin{array}{c}2,65- \\
5,77\end{array}$ & $89,9-105$ \\
\hline
\end{tabular}

Trong khoảng nồng độ từ 5,00 - $1.000 \mu \mathrm{g} / \mathrm{L}$, cả Nisin $\mathrm{A}$ và Nisin $\mathrm{Z}$ đều cho hệ số tương quan $\mathrm{R}^{2}>0,9995$. Trong đó, độ chệch (bias) cho phép là nhỏ hơn $( \pm$ ) $15 \%$ [11]. Như vậy, các điểm chuẩn có độ chệch trong khoảng từ - 3,15 đến $+7,26 \%<( \pm) 15 \%$, giá trị $\mathrm{P}_{\text {value }}$ của hệ số a và $\mathrm{b}<0,05$ cho thấy đường chuẩn, độ lặp lại và độ thu hồi đều đạt theo yêu câu của $\mathrm{AOAC}$ [11].

\section{5. Đánh giá hàm lượng Nisin $A$ và Nisin $Z$ trong mẫu thực tế}

Kết quả phân tích đông thời hàm lượng Nisin $\mathrm{A}$ và Nisin $\mathrm{Z}$ trong 25 mẫu thực phẩm dinh dưỡng thu thập ngẫu nhiên tại Hà Nội được thể hiện trong Bảng 4.

Bảng 4. Kết quả phân tích đồng thời hàm lượng Nisin A và Nisin Z trong các mẫu thực phẩm dinh dương

\begin{tabular}{lcccc}
\hline Đối tượng & $\begin{array}{c}\text { Số mẫu } \\
\text { phân tích }\end{array}$ & $\begin{array}{c}\text { Số mẫu } \\
\text { Phát hiện }\end{array}$ & $\begin{array}{c}\text { Hàm lượng Nisin A } \\
(\mu g / \mathbf{k g} / \mathrm{L})\end{array}$ & $\begin{array}{c}\text { Hàm lượng Nisin } Z \\
(\mu \mathrm{g} / \mathrm{kg} / \mathrm{L})\end{array}$ \\
\hline $\begin{array}{l}\text { Sũa lỏng } \\
\text { Sũa bột }\end{array}$ & 5 & 1 & 105,7 & 180,5 \\
Mẫu bơ & 5 & 0 & - & - \\
Phomat & 5 & 1 & 92,35 & - \\
Bột dinh duỗng & 5 & 0 & - & - \\
\hline
\end{tabular}

Ghi chú: (-): nhỏ hơn giới hạn phát hiện của phương pháp

Kết quả phân tích 25 mẫu thực phẩm dinh dưỡng đã phát hiện 02 mẫu có chứa chất phân tích Nisin $\mathrm{A}$ và Nisin $\mathrm{Z}$ nhưng đều nằm trong ngưỡng giới hạn cho phép theo Quy định của $\mathrm{B}$ ộ Y tế [1]. Các mẫu không phát hiện chất phân tích đều cho hiệu suất thu hồi khi thêm chuẩn ở các mức nồng độ $10 \mu \mathrm{g} / \mathrm{L}, 20 \mu \mathrm{g} / \mathrm{L}$ và $50 \mu \mathrm{g} / \mathrm{L}$ nằm trong khoảng $80,1-105 \%$, minh chứng hiệu quả của phương pháp.

\section{KẾT LUẬN}

Nghiên cứu đã thành công trong việc xác định hàm lượng Nisin $\mathrm{A}$ và Nisin $\mathrm{Z}$ trong mẫu thực phẩm dinh dưỡng bằng phương pháp sắc kí lỏng ghép nối hai lần khối phổ (LC-MS/MS). Quy trình phân tích được tối ưu cho nền mẫu thực phẩm dinh dưỡng có chứa nhiều thành phân gây ảnh hưởng. Phương pháp phân tích cũng đã được thẩm định về độ đặc hiệu, đường chuẩn, độ lặp lại, độ chính xác và giới hạn phát hiện. Kết quả phân tích 25 mẫu thực phẩm dinh dưỡng 
đã phát hiện 02 mẫu có chứa đồng thời hàm lượng Nisin $\mathrm{A}$ và Nisin $\mathrm{Z}$ với hàm lượng nằm trong ngưỡng cho phép theo quy định của Bộ Y tế. Phương pháp cho thấy có hiệu quả cao trong việc xác định đồng thời Nisin $\mathrm{A}$ và Nisin $\mathrm{Z}$ trong mẫu thực phẩm dinh dưỡng, góp phần đảm bảo chất lượng các sản phẩm này.

\section{TÀI LIỆU THAM KHẢO}

[1]. Thông tư 24/2019/TT-BYT, Quy định về quản lý và sử dụng phụ gia thực phẩm, Bộ Y tế, 2019.

[2]. J. W . Mulders, I. J. Boerrigter, H. S. Rollema, R. J. Siezen, and W. M. de Vos, "Identification and characterization of the lantibioticnisin Z, a natural nisin variant," European of Journal Biochemistry, vol. 201, no. 3, pp. 581-584, 1991.

[3]. Soliman, L.C. and K.K. Donkor, "Method development for sensitive determination of Nisin in food products by micellar electrokinetic chromatography," Food Chemistry, 119(2), pp. 801- 805, 2010.

[4]. N. Schneider, K. Werkmeister, M. Pischetsrieder, "Separation and determination of closely related lantibiotics by micellar electrokinetic chromatography," Journal of Separation Science, vol. 32, no. 17, pp. 2993-3000, 2009.

[5]. Tiêu chuẩn Việt Nam TCVN 10137:2013, Xác định hàm lượng Nisin $\mathrm{A}$ bằng sắc ký lỏng phổ khối lượng (LC-MS) và sắc ký lỏng - phổ khối lượng hai lần (LC-MS-MS), Tônng Cục Tiêu chuân Đo lường Chất lượng thẩm định, Bộ Khoa học và Công nghệ công bố, 2013.

[6]. F. Fuselli C. Guarino, A. L. Mantia L. Longo, A. Faberi and R. M. Marianella, "Multidetection of preservatives in cheeses by liquyd chromatography-tandem mass spectrometry," Journal of Chromatography B, vol. 906, pp. 9-18, 2012.

[7]. K. Y. Ko, S. R. Park, C. A. Lee and M. Kim, "Analysis method for determination of Nisin A and Nisin $\mathrm{Z}$ in cow milk by using liquyd chromatography-tandem mass spectrometry," Journal of Dairy Science, vol. 98, no. 3, pp. 1435-1442, 2015.

[8]. N. Schneider, K. Werkmeister and M. Pischetsrieder, "Analysis of Nisin A, Nisin Z and their degradation products by LCMS/MS," Food Chemistry, vol. 127, no. 2, pp. 847-854, 2011.

[9]. W. Liu and J. N. Hansen, "Some chemical and physical properties of nisin, a small-protein antibiotic produced by Lactococcus lactis," Applied and Environmental Microbiology, vol. 56, no. 8, pp. 2551 - 2558, 1990.

[10]. S. Suda, D. Field and N. Barron, "Antimicrobial peptide production and purification," Protein Chromatography, Humana Press, New York, NY, pp. 401-410, 2017.

[11]. AOAC. Appendix F: Guidelines for standard method performance requirements. AOAC official methods of Analysis, 9, 2012. 


\title{
Simultaneous determination of Nisin A and Nisin Z in nutritional food by liquid chromatography tandem mass spectrometry (LC-MS/MS)
}

\author{
Tran Thi Huong ${ }^{1,2}$, Le Thi Thuy ${ }^{3}$, Vu Thi Trang ${ }^{3}$, Nguyen Thi Anh Huong $^{1}$, Le Thi Hong Hao ${ }^{1,3}$ \\ ${ }^{1}$ University of Science, Vietnam National University, Hanoi, Vietnam \\ ${ }^{2}$ Disease Control Center, Nam Dinh, Vietnam \\ ${ }^{3}$ National Institute for Food Control, Hanoi, Vietnam
}

A method for the simultaneous determination of Nisin A and Nisin $\mathrm{Z}$ in nutritional products by LC-MS/MS has been developed. Sample treatment was performed by ultrasonic extraction using a mixture of $0.1 \mathrm{M} \mathrm{CH}_{3} \mathrm{COONH}_{4}$ buffer solution - $1.0 \mathrm{M} \mathrm{NaCl}$ (pH 2.0): $\mathrm{MeOH}$ $(1: 1, \mathrm{v} / \mathrm{v})$ at room temperature for 10 minutes. Extracts were then cleaned through $\mathrm{C} 18$ solid phase extraction column (500 mg, $3 \mathrm{~mL}$ ) and analyzed on LC-MS/MS instrument using a C18 column $(100 \mathrm{~mm} \times 2 \mathrm{~mm} \times 1.7 \mu \mathrm{m})$ with ESI $(+)$ mode. The method was validated for linear calibration curve in the range of $10-1,000 \mu \mathrm{g} / \mathrm{L}$; relative standard deviation (RSD) $2.12-5.77 \%$; recovery 80.1 - 105\%, meeting AOAC requirements. The method has been applied to analyze 25 samples of nutritious food collected from the local markets (including: liquid milk, powdered milk, butter, cheese, nutritious powder), showing that two samples were detected both Nisin A and Nisin Z.

Keywords: LC-MS/MS, Nisin A, Nisin Z, food, nutritional food. 